\title{
Editorial
}

\section{Towards Student Centered Learning Activities}

The adoption of ideas those are new to those considering them for the first time, takes time. This edition of the journal demonstrates a number of academics taking an idea and testing its application in their educational practice. The authors have provided evidence of their attempts to focus on the student's learning needs and demonstrate a commitment to authenticity in the designs of stimulus material for their learning activities. In this way they are also demonstrating a commitment to meeting the consumer or patient needs for whom their graduates will ultimately care. The papers tell us something about the abilities that the students are embracing and developing: being thoughtful, adopting a critical stance, assuming responsibility for their own learning, assuming values consistent with empathy and communicating in a manner that is meaningful to those with whom they are interacting. In showing how academics might let go of some old behaviours and adopt new ones, the papers all align to the principles behind practice based learning, whether the practice centres on an action oriented discipline or the more liberal arts that equally demand an enquiry based approach to learning and teaching.

Treloar et al highlight the notion that many of the situations encountered in mental health nursing are unpredictable and circumstances change in an instant. It is difficult to develop and implement a management plan or advocate one behavioral approach to safe and therapeutic care. The authors present a workshop strategy for the collection of storylines from actual practice. The storylines inevitably reflect the dynamism and messiness of practice. Sometimes what is needed from health professionals in the complexity of mental health practice are thoughtful but seemingly 'aberrant' strategies that nevertheless are based on a sound understanding of the principles of safe practice. The ability to adapt communication styles and try new ways of therapeutic engagement need to be uppermost in the minds of the carers of the particular person who is being cared for.

Focusing on the liberal arts, Kim cautions that many universities want to encourage the inclusion of more 'general' studies options within curricula that are often heavily oriented to a specific discipline that has prescribed vocational 


\section{Editorial}

options. Frequently the more liberal options are offered as 'electives' but in other instances might be part of a suite of resources i.e., sociology, that supports a core of studies e.g., in occupational therapy or nursing. Kim suggests that while all disciplines in South Korea are being encouraged to embrace a greater focus on student centered and selfdirected learning, academics struggle to find resources to support them in changing their own direction. She explored options and describes the path taken to introduce e-learning, suggesting that one does not have to work alone; collaboration on innovation among peers and across universities is possible.

Chiang et al from Hong Kong undertook a quasi-experimental design to compare outcomes of a study involving two classes of pre-registration nursing students, one group undertaking a traditional approach and the other embracing the use of high fidelity technology. The researchers were looking for evidence of differences in the learning experience and outcomes around either the involvement of an advanced Naso-Gastric Tube simulator, or an education event that involved 'demonstration' training. The authors show that while it is difficult to demonstrate 'cause and effect' in teaching and learning events, careful construction of those events with the student engagement and learning outcomes in mind, one can enhance 'knowing about' a technique and 'knowing how' to safely apply the technique when transferring newly acquired skills to actual patient care.

McMillan and Park have provided a number of elements for consideration when making decisions about what can be simulated in classroom and laboratory activities, what is best derived from actual practice and how academics might best link theory and practice. Like Chiang et al they suggest a need for careful consideration of the best way to achieve optimal outcomes for student learning. It is important to note that the use of technology is not necessarily the best addition to a learning event. The selection of meaningful practice situations across the entire program needs to be based on agreed upon criteria. The selection criteria need to reflect the conceptual framework of the curriculum. Student engagement is critical factor in the learning journey. 
Jung and Kong suggest that after the application of a Creative PBL model, an experimental group showed a significant increase in their abilities in communication, resolving (finding solutions) and empathy when compared to their control group. They concluded that their processes for learning improved the abilities of the students around communication, a solutions orientation to learning (resolving problems) and enhanced their awareness of and capacity for empathetic behaviors. The researchers also argued that the widespread reliance on didactic lecture traditional teaching methods in South Korea and elsewhere centers on short-term acquisition of knowledge from textbooks and that this has limited value for lifelong learning. Using different stimulus material, the CPBL model led to more comprehensive learning outcomes consistent with improved abilities relevant to actual professional practice. Their analogy of the seed box suggests many things to the reader. The seed could be the student with the potential to grow given the right attention consistent with needs. The seeds could equally represent a repository of learning issues. Once extracted for nurturing, the students needed to take these issues, and test their knowledge about them and set their own learning objectives on a 'need to know' basis. The lecturer becomes a coach, guiding the students in a particular direction and acting as one of many resources available in today's world. The teacher as coach needs to guide the student to test the worthiness and relevance of readily accessible information.

The research activities reported on in this edition are encouraging as is the willingness of academics to abandon long held practices to attempt to engage and motivate the current generation of students in learning for life.

Emeritus Professor Margaret McMillan

Editor in Chief

School of Nursing and Midwifery

University of Newcastle, Australia 
